\title{
Ambitions for palliative and end-of-life care
}

\author{
Author: Bee Wee
}

The publication of the Ambitions for palliative and end of life care: a national framework for local action 2015-2020 in September 2015 represents a new milestone in England for all who want to ensure that everyone with advanced, progressive, life-limiting illness has the best possible experience of care throughout their remaining life, and in death. ${ }^{1}$ This comes less than 30 years after palliative medicine was formally recognised as a specialty within the Royal College of Physicians and less than 10 after the term 'end-of-life care' was formally defined as 'last year of life' in the first national End of Life Care Strategy in $2008 .^{2}$ In practice, although the definition of 'end-of-life care' is time-based and 'palliative care' is needs-based, the approach is similar. Like respiratory, cardiac, renal and most other specialties, palliative care has both generalist and specialist components, so all doctors need to be able to deliver this kind of care well, involving palliative medicine specialists when they reach the limits of their competence and confidence.

This issue of Clinical Medicine carries a piece on the National Institute for Health and Care Excellence (NICE) clinical guideline for care of the dying adult (NG31). ${ }^{3}$ It is important to understand the historical context for this guideline in particular. In July 2013, the Neuberger report More care less pathway recommended the withdrawal of the use of the Liverpool Care Pathway (LCP) for the dying patient in England. ${ }^{4}$ This was an independent report commissioned by the then minister for care and support, Norman Lamb, in response to concerns raised by increasing numbers of families about the poor care that their relatives had received. The LCP was an approach to care developed during the 1990s to systematically embed the principles of hospice care within acute hospital settings. The Neuberger report concluded that 'when the LCP is used properly, patients die a peaceful and dignified death' but that 'implementation of the LCP is sometimes associated with poor care'. In particular, they advocated against the use of the term 'pathway'.

In response to this report, the Leadership Alliance for the Care of Dying People (LACDP), consisting of statutory, regulatory and voluntary national bodies and the royal colleges, published One chance to get it right in $2014 .{ }^{5}$ This response emphasised the importance of individualised care for the dying person, and those important to them, and set out key priorities of care: recognition of the possibility that dying is imminent

Author: ${ }^{A}$ consultant in palliative medicine, Oxford University Hospitals NHS Foundation Trust, Oxford, UK and the communication thereof; sensitive communication; involvement in decision making; support of families and those important to the dying person; and planning and delivering individualised care. Each LACDP signatory agreed to play its part in delivering the commitments made in the response, focusing on ensuring these priorities are achieved, eg Care Quality Commission's decision to designate end-of-life care as one of its core areas for hospital inspection, and the National Institute for Health Research commissioning an annotated bibliography underpinning each of these priorities to help clinicians understand the strength of existing evidence (http:// papas.cochrane.org/palliative-care-database).

All this was happening in the aftermath of the Francis Report ${ }^{6}$ and its serious concerns about patient safety. The NHS England Never Events Task Force, in its report on commissioning for safer surgery, pointed out that while checklists have promoted systematic change, they are of limited use when they are treated as tick-box exercises: '[it] is not an end in itself, but a tool to promote systemic change and prompt safer behaviour'. ${ }^{7}$ This has resonances with the way the LCP had come to be regarded in places where it was poorly implemented and where staff were inadequately trained and supported to deliver sensitive, compassionate, individualised care.

The publication of NG31 in December 2015 represents the fulfilment of the commitment made by NICE as part of the Leadership Alliance. ${ }^{8}$ It is important to recognise that the guideline does not set out to cover the totality of care of the dying person - instead it focuses on a few specific areas, for which evidence needed to be carefully examined and set out. This was always going to be a difficult task, because of the paucity of solid research evidence, the inherent uncertainties and complexities of dying, the need for subjective 'at the bedside' judgements, regular review and an individualised approach to care.

Like the Neuberger report and the Leadership Alliance's response, NG31 is about care in the very last days of life. We need to extend this focus to earlier months or even years in the trajectory, ie when it is known that the patient has a limited and shortened life expectancy, and when good palliative and endof-life care have much to offer the individual and those close to them. How can we improve our health and care services so that they have the kind of experience we would want for ourselves and our loved ones when we are in that situation?

There are challenges inherent in palliative and end-of-life care, whether in the last days of life, or earlier in the illness. First, the numbers are increasing. There will be more people living longer with frailty and with multiple conditions, facing 
limited life expectancy who have palliative care needs. At least a proportion of them will need specialist palliative care. Second, securing a strong evidence base on which to design treatment, care and services is difficult. These patients are frail with a rapidly deteriorating baseline and diminishing energy; recruitment is difficult because of understandable gatekeeping by family and staff. Research in those close to death is particularly difficult, hence the paucity of evidence to inform NG31. Third, it is difficult to get suitable measurements of quality. Length of survival is unhelpful here. Place of death is data easily available through death registration, so it has been used as a proxy measure of quality. Most thoughtful people will recognise that the location of death (even when it matches patient preference) does not reflect the quality of the care or whole experience. The danger of relying on one suboptimal metric is that treatment, care and service improvements can become too focused on improving that statistic, thus missing the point altogether. Fourth, palliative and end-of-life care has to be available and delivered in all care settings, so the task of educating, supporting and continually refreshing training for all groups of staff in all settings is huge. Finally, funding is more complicated than for some areas of medicine. Social care forms a large and essential part of end-of-life care. Specialist palliative care, within voluntary and NHS services, rely on charitable donations for a significant part of their service revenue.

Given the scale of the challenges, and the consequences of the Health and Social Care Act 2012, we need to redefine and reframe our approach to the provision of palliative and end-of-life care. The Ambitions for palliative and end of life care mentioned earlier sends clear signals. It is a 'national framework for local action' - so it provides a national-level steer by describing the vision, in the form of six high-level ambitions, and the direction of travel, but makes clear that achieving this requires local leadership and concerted effort. It sets expectations for individuals, groups and organisations within the system - statutory, voluntary or community; and commissioners, clinicians, care staff, volunteers or public. It identifies foundations for all six ambitions collectively and building blocks for each, so it is easy for individuals and organisations to spot where they can contribute.

The first four ambitions are focused around the individual and framed as outcomes:

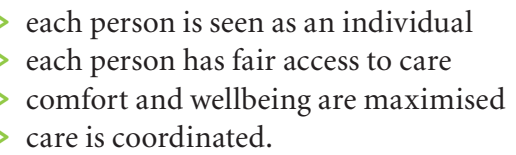

A fifth ambition focuses on staff being prepared, in terms of knowledge, skills, attitude and support, to care, and the final one challenges the wider community: each community is prepared to help. Unlike the 2008 National Strategy, the Ambitions for palliative and end of life care covers all ages and spans health and social care. Developed as a collaboration of 27 national organisations, across health and social care, statutory and voluntary, and with professional and patient voices, its collective will and influence are strong. The framework incorporates findings and recommendations of the many reports, reviews and inquiries into palliative and end-of-life care in recent years, so it simplifies the 'reading landscape' and aims to stimulate action.

The six high-level ambitions set out in the Ambitions for palliative and end of life care framework could be applied easily to any other area of healthcare. Equally, the ability and capacity to deliver good palliative and end-of-life care provide the means to improving treatment and care across all specialties, and in all settings.

\section{References}

1 National Partnership for Palliative and End of Life Care. Ambitions for palliative and end of life care: a national framework for local action: 2015-2020. September 2015. Available online at http://endoflifecareambitions.org.uk/ [Accessed 30 March 2016].

2 Department of Health. End of Life Care Strategy. London: DoH, 2008.

3 Hodgkinson S, Ruegger J, Field-Smith A, Latchem S, Ahmedzai $\mathrm{SH}$. Care of dying adults in the last days of life. Clin Med 2016;16:254-8.

4 Neuberger J. More care less pathway: a review of the Liverpool Care Pathway. London: DoH, 2013.

5 Leadership Alliance for the Care of Dying People. One chance to get it right: improving people's experience of care in the last few days and hours of life. London: DoH, 2014.

6 Francis R. The Mid Staffordshire NHS Foundation Trust Public Inquiry. London: HMSO, 2013.

7 NHS England Never Events Taskforce. Standardise, educate, harmonise: commissioning the conditions for safer surgery. Leeds: NHS England, 2014.

8 National Institute for Health and Care Excellence. Clinical guidelines for care of the dying adult in the last days of life (NG31). London: NICE, 2015.

Address for correspondence: Prof B Wee, Sir Michael Sobell House, Churchill Hospital, Oxford OX3 7LE, UK. Email: bee.wee@ouh.nhs.uk 